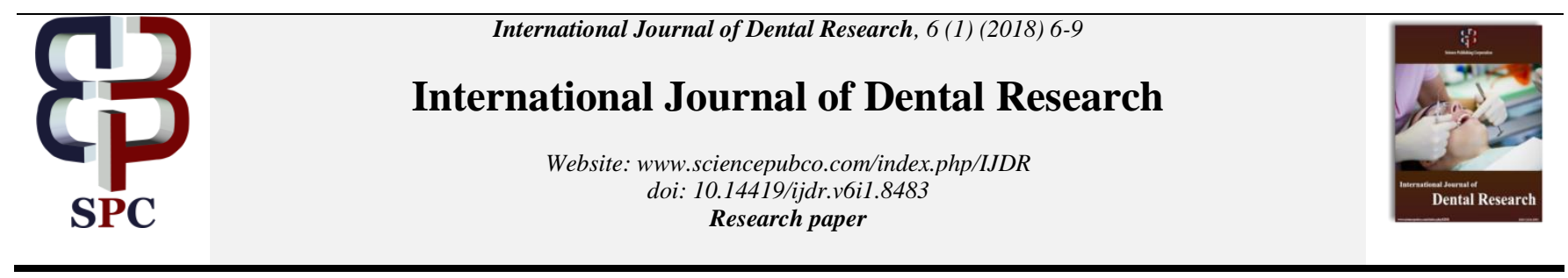

\title{
Niobium - plausiblity for use in restorative dentistry
}

\author{
A. Meenakshi ${ }^{1 *}$, C. Sabarigirinathan ${ }^{2}$, V.P Kiruthiga ${ }^{3}$ \\ ${ }^{1}$ Professor, Department of Prosthodontics, Tamilnadu govt. dental college and hospital. \\ ${ }^{2}$ Head of department, Department of prosthodontics, Tamilnadu govt. dental college and hospital. \\ ${ }^{3}$ Post graduate student, Department of prosthodontics, Tamilnadu govt. Dental college and hospital \\ *Corresponding author E-mail: drkmeena6@gmail.com
}

\begin{abstract}
Rare earth elements have gained enormous popularity in the recent years because of their excellent mechanical properties along with their inertness, which easily makes them biocompatible in the oral environment. Niobium is in use in the biomedical field in small proportions with other primary elements but not as principal constituent. In this review the credibility of the element Niobium as a restorative material its advantages over others currently in use in dentistry is explained by reviewing the literature. This paper also reviews about the castability and biocompatibility of niobium $(\mathrm{Nb})$ in detail.
\end{abstract}

Keywords: Niobium; Casting; Grain Refining; Corrosion Resistance; HSLA (High-Strength Low Alloyed Steel)

\section{Introduction}

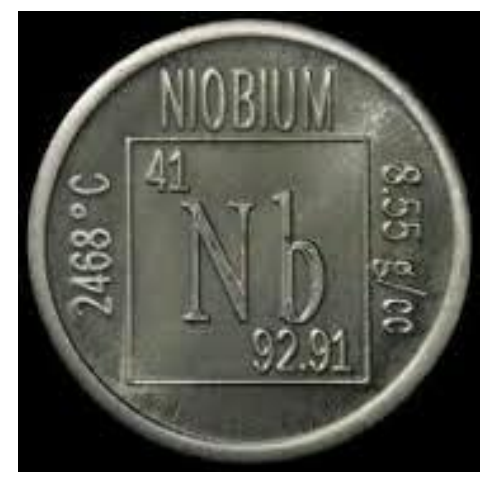

It is only fitting to start this review article with the quote of sir William's cook, a British chemist 'The rare-earth elements perplex us in our research's baffles us in our speculation, haunt us in our very dreams. They stretch like an unknown sea before us mocking, mystifying and murmuring strange revelations and possibilities. In this review the credibility of the element Niobium as a restorative material, its advantages over others currently in use in dentistry is explained by reviewing the literature. Rare-earth elements have started a new era with all its promising material properties. Niobium with its high strength \& low density has made HSLA steel possible and has revolutionised the automobile sector. And now it has infiltrated the medical field as implants, in MRI machines and various surgical instruments due to its excellent biocompatibility and corrosion resistance.

\section{History}

Ni was discovered by Charles Hatchet in 1801, and he named it columbium since it came from the coloumbite ore ${ }^{1}$.

It later was given the name Niobium by Heinrich Rose (17951864) from the Greek word 'Niobe', the daughter of Tantalus since they had similarities in properties.

In 1933, was utilized to stabilize stainless steel against inter granular corrosion.

1970, technological application as super alloys

2000-2010, widely used in energy and automotive sector

Recent, micro alloyed steels, super alloys, medical implants, MRI, immunoscintigraphy, electrolytic and ceramic capacitors.

\section{Properties}

\subsection{Physical}

Melting point: $4490.6 \mathrm{~F}$

Boiling point: $8571.2 \mathrm{~F}$

Density: $8.57 \mathrm{~g} / \mathrm{cm} 3$

\subsection{Mechanical}

Young modulus: $104.9 \mathrm{GPa}$

Shear modulus: $37.5 \mathrm{GPa}$

Specific heat capacity: $265 \mathrm{j} \mathrm{kg}^{-1} \mathrm{k}^{-1}$ 


\subsection{Chemical}

Atomic no.: 41

Atomic mass: 92.91

Isotopes: 14

\section{Global market}

Three main producers,

Brazil, Canada, and others

\section{Ferroniobium}

It is an iron niobium alloy with a niobium content of $60-70 \%$. It is the main source of niobium alloying of HSLA steel and covers more than $80 \%$ of world-wide niobium production. Ferroniobium can effectively double the strength and toughness as well as reduce the weight of the alloy and increases the weldability.

It vastly enhances the anti-corrosive properties even better than carbon steel. Moreover it shows improved temperature resistance, oxidation resistance, creep resistance, as well as reducing erosion at higher temperatures.

\subsection{Production of Ferroniobium}

$\mathrm{Ni}$ is first mined from pyrochlore deposits and is then processed into Niobium pentoxide. This is mixed with iron oxide as well as alumina and then reduced in a aluminothermy reaction to niobium and iron. The resulting ferronoibium is purified by electron beam melting.

\subsection{Supplid in: powder or briquettes $(2 \mathrm{~mm}-50 \mathrm{~mm})$}

For any material to be a successful restoration in vivo environment, it should be biocompatible and have advantageous material properties over others. The following are details about the mechanical properties,

\section{Discussion of material properties}

\subsection{Micro alloying}

$\mathrm{Ni}$ in small amounts provides grain size refinement of steel during thermo mechanical heat forming, lowering the gamma to alpha transition temperature. It increases strength, toughness and ductility ${ }^{2}$.

The grain refining effect of niobium is due to delaying or preventing recrystallization in the last hot forming steps. Flattened grains as well as high dislocation density of the austenite enhances the ferrite nucleation rate and reduces the grain growth. The combined effect leads to a particularly fine grained transformation structure. Microalloying in titanium is carried out with boron which further renders gamma titanium aluminide easily castable.

Niobium has a large atomic radius (metallic radius $146 \mathrm{pm}$ ) which is capable of stretching the austentic lattice to such an extent and along with its grain refining effect providing a high yield strength. It also reduces the precipitation of chromium carbide thereby decreasing pitting corrosion of steel. $\mathrm{Nb}(0.02-0.06)$ is a very strong ferrite strengthener and also $\mathrm{Nb}(\mathrm{C}, \mathrm{N})$ delays alpha to gamma transformation ${ }^{3,4}$

\subsection{Improving castability}

Castability of gamma titanium aluminide is brought about by adding high niobium inclusions and low $\mathrm{Cr}$. They also show improved strength and ductility.

\subsection{Shell cast moulding}

There are quite a few disadvantages with normal casting methods of niobium like free silica build up and since chemically reactive elements such as niobium silicide are casted, oversized cast may result. The above are eliminated if a shell cast moulding is used.

Method: The mould comprises of a shell for containing the molten metal formed from at least one of the yttrium silicates, zirconium silicates, hafnium silicates and rare-earth silicates. It also includes a face coat in the inner surface of the shell that contacts the molten metal containing one of the above mentioned ${ }^{4}$.

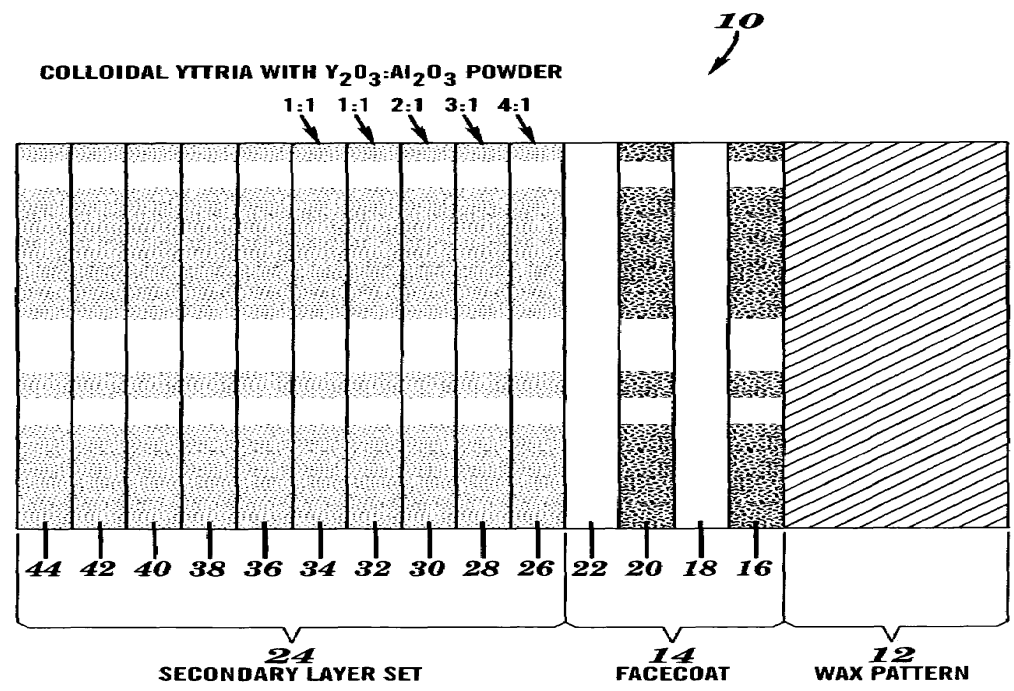

Fig. 1: Shell Cast Moulding schematics. 


\subsection{Biocompatibility}

Niobium shows excellent biocompatibility. It readily forms a stable and protective oxide layer akin to Titanium. Eisenbarth et al ${ }^{5}$ conducted studies using vascular cell lines, in which niobium was compared to a number of metals using murine skull osteoblast like cells and bovine aortic endothelial cells and niobium performed better than $\mathrm{Ti}$ in terms of proliferation and mitochondrial activity while both metals were similar in reaction to cell volume and morphology changes. In one study, the attachment of human osteoblastic cells was compared to medical grade stainless steel and the tissue culture plastic and the absolute number of attached cells after a culture period of $24 \mathrm{hrs}$ concluded that $\mathrm{Nb}$ film was superior to ss and the control indeed; there were 20 more cells on the $\mathrm{Nb}$. In addition faster growth rate of cells on niobium and an excellent metabolic function was observed. And also cells differentiated faster from a proliferative state.
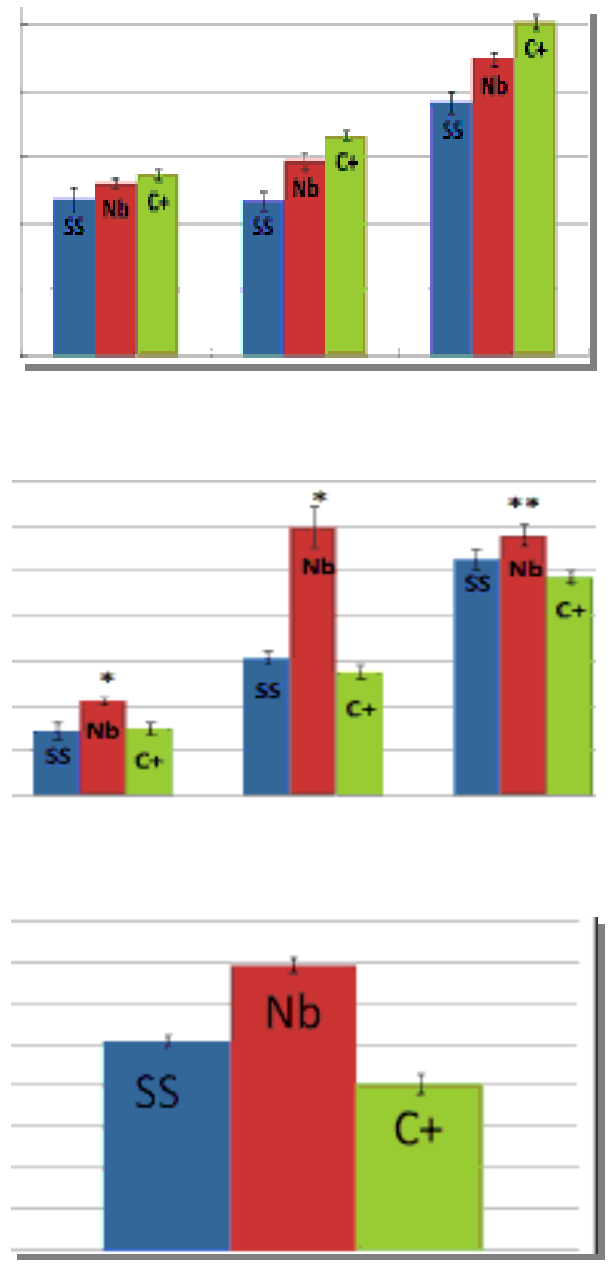

Fig. 2: 1). Cell Viability. 2). Cell Proliferation. 3). Cell Adhesion.

SS - Stainless steel. Ni - Niobium. C - Carbon.

Water contact angle plays an important role in biocompatibility of materials; more the water contact angle more is its biocompatibil- ity. Niobium shows better contact angles than titanium says one study.

One study shows that commercially pure niobium shows a slightly higher removal torque than titanium. After the implants were inserted in the rabbits' bone and a healing period of three-month removal torque of 32.9 for $\mathrm{Ni}$ whereas 25.3 for $\mathrm{Ti}$ were recorded indicating a good bone contact.

One research says niobium pentoxide has high catalytic activity in the esterification of acetic acid (Lizuka et al 1986) as well as being a sufficient catalyst in the trans esterification of beta keto ethers, which are important intermediates of organic synthesis (de Sairre et al 2005).

Niobium pentoxide has shown bioactive properties like hydroxyl appathite crystal growth when in contact with human saliva -R.L karlinsey A.T hara, K yi E.W duhn

\subsection{Niobium, as dental implants}

Dental implants have grown steadily rising consistently over the last 20 years. One study states that nearly 1 million implants are placed annually worldwide. Implant failures are often attributed to periimplantitis, loss of osseointegration, biomechanical failures.

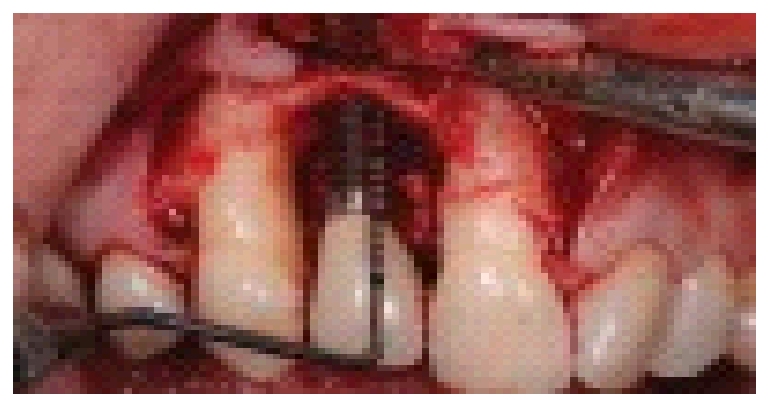

Fig. 4: Periimplantitis.

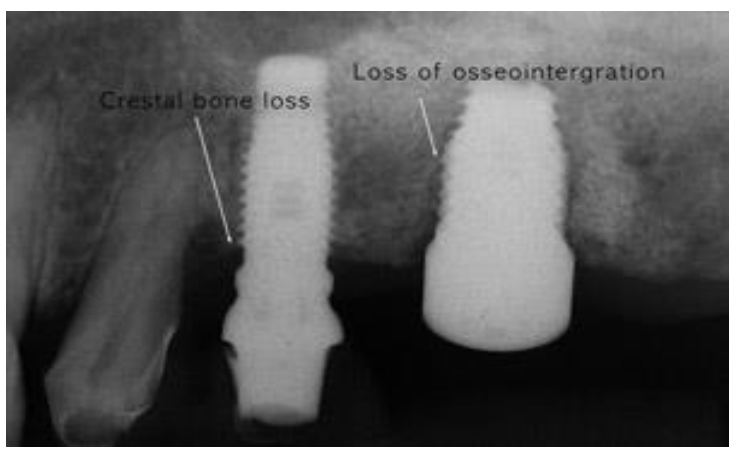

Fig. 5: Loss of Osseointegration. 


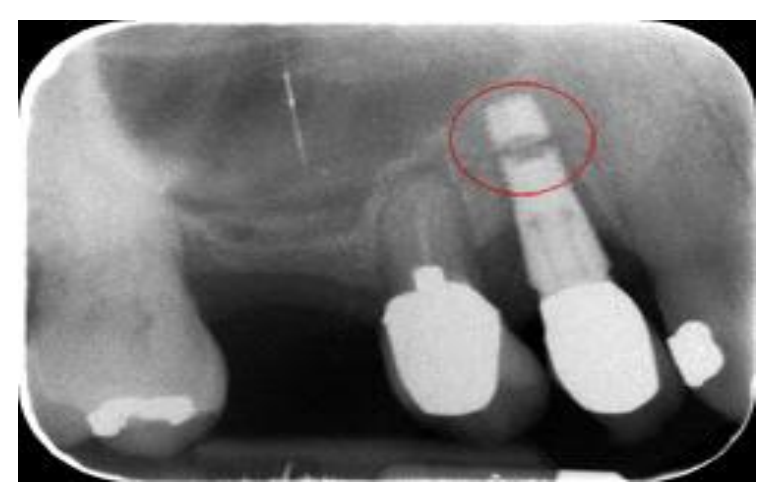

Fig. 6: Biomechanical failure.

Despite the high success rates of implants in longitudinal studies, failures still occur and are largely attributed to lack of osseointegration. Researchers have been performed widely, and a number of innovative implants with a number of modifications are available, and the researchers continue for best material and methods to improve osseointegration.

Modification of the implant surface coatings with significantly biocompatible materials has been researched and researched. Niobium as one such material has shown promise.

Niobium metal as a base demonstrated bioactivity of the anodised niobium oxide coating in a variety of solutions, including calcium phosphate solution, stimulated and human saliva, and human blood and a small lattice mismatch of only1. 1percent between the niobium pentoxide phase and hydroxyl appathite suggested an influence on mineral nucleation.

Anodisation improves niobium oxide growth says one research, but longer anodisation periods may cause delamination. According to the study, SEM imaging showed that implants anodized for $1 \mathrm{hr}$ in a $0.1 \mathrm{HF}$ aqueous solution reveals best results.

One study says, a porous $\mathrm{Ti} \mathrm{Nb}$ alloy with pores ranging from $200 \mu \mathrm{m}$ to $500 \mu \mathrm{m}$ showed favourable bone ingrowth, and its compressive strength was similar to cortical bone and the elastic modulus closer to the cancellous bone with no significant cytotoxicity in rabbit bone marrow mesenchymal cells and according to IL 6 levels. There was no obvious inflammatory response and cell adhesion and proliferation on the surface of the alloy was good.

\section{Conclusion}

As stated by Stephen's castor, 'rare-earth earth elements are neither rare nor earth'. The supply to meet the demand is proposed as well as steps have been dealt with for furthering production, and it is not just dust, having many remarkable features. It further researches will throw light into this element and can be used as a successful restorative in the forth coming years.

\section{References}

[1] CharlesHatchet: The discoverer of niobium Educación Química, Volume 26, Issue 4, Pages 346-355 Jaime Wisniak.

[2] Microalloyed steels T. N. Baker to cite this article: T. N. Baker (2016) Microalloyed steels, Ironmaking \& Steelmaking, 43:4 264-307, https://doi.org/10.1179/1743281215Y.0000000063.

[3] TMS A. Ray and H. K. D. H. Bhadeshia Published Online: 6 Nov. 2015HSLA Steels 2015, Microalloying 2015 \& Offshore Engineering Steels 2015: Conference Proceedings.

[4] Shell mould for casting niobium silicide alloy and related composition and process US patent7296616B2.

[5] Nanostructured niobium oxide coatings influence osteoblast adhesion E. Eisenbarth, D. Velten,M. Müller,R. Thull,J. Breme 20 June 2006.
[6] Biocompatibility of Niobium Coatings René Olivares-Navarrete 1, Jhon Jairo Olaya 2, Claudia Ramírez 3 and Sandra Elizabeth Rodil research gate January 2011.

[7] TMS A. Ray and H. K. D. H. Bhadeshia Published Online: 6 Nov. 2015HSLA Steels 2015, Microalloying 2015 \& Offshore Engineering Steels 2015: Conference Proceedings.

[8] Potential use of porous Ti Ni alloy in orthopaedic implants -liam $\mathrm{xu}$, xiao jun wang,xu wang, zia zhang huang, Hassan mohammed, zin ma, olan de tiaoNi based coatings for dental implants $\mathrm{G}$. Ramirez S.E rydl, H. arzate, S.muhl, J.J olay.

[9] Gamma titanium aluminide rendered castable by low $\mathrm{Cr}$ and high Niobium additives US patent 5213635A.

[10] A removal torque histomorphic study of commercialy pure $\mathrm{Ni}$ and Ti implants in rabbit bone C.B johannson T. Albertson.

[11] Stochiometrty, structure and physical properties niobium silicide wayne, fisher, M.J sclerio, Christian klienberg 2011.

[12] Process of forming niobium and boron containing Ti aluminide US patent 5082506 .

[13] Nano structured niobium oxide coatings influence osteoblatic adhesion eisenbarth et al D. velton M.muler R thul J breme.

[14] Bioactivity of novel self-assembled crystalline niobium pentoxide microstructures in stimulated human salivas biomedical maerials vol. $12006 \mathrm{pg} 16-23$.

[15] Biocompatibility of niobium coatings Rene Olivares navvarette,john Jairo olaya, Claudiya Ramirez,Sandra Elizabeth rodil research gate January 2011. 